\title{
Employing Participatory Action Research to Augment Software Development for Rural Communities
}

\author{
Siang-Ting Siew \\ Faculty of Computer Science and Information Technology \\ Universiti Malaysia Sarawak \\ 94300 Kota Samarahan \\ Sarawak, Malaysia \\ s.siangting@gmail.com
}

\author{
Alvin W. Yeo \\ Institute of Social Informatics and Technological Innovations \\ Universiti Malaysia Sarawak \\ 94300 Kota Samarahan \\ Sarawak, Malaysia \\ alvin@isiti.unimas.my
}

\begin{abstract}
The paper proposes a software development methodology which also employs the participatory action research (PAR) method given that PAR has been successfully employed in projects in rural communities. Arguments for this approach are provided, discussed in the context of software development for rural communities.
\end{abstract}

Software development methodology, participatory action research, rural applications

\section{TELECENTRES IN RURAL AREAS}

Telecentres are established to furnish the rural communities with information and communication services, but many fail as the projects are not need-driven. The United Nations Economic and Social Commission for the Asia Pacific (UNESCAP) in a study of 11,160 telecentres in 16 countries in Asia Pacific region showed that $54 \%$ of the telecentres provided access to ICTs (UNESCAP, 2008) (refer Figure 1). In addition, telecentres were used for many areas such as ICT training, providing access to online learning, and e-Health services. It stands to reason many software applications are being created for specific community use as well as to allow the community to access information as mentioned above.

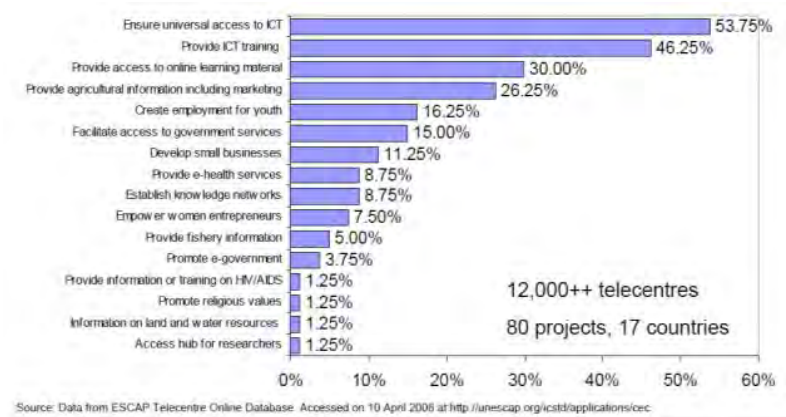

Figure 1: Distribution of telecentre projects by area of intervention, Year 2008.

Also, these applications may also be in the local languages as Roman \& Colle (2002) also argued that a telecentre may also lose relevance if information provided is in unfamiliar or inappropriate languages or dialects; especially when most of the information on available online is in English. Thus, of importance, is the need to introduce appropriate ICTs, that is relevant to the community; building good quality and relevant softwares by addressing their need in order to enhance the work of the telecentres in the communities.

\section{GOOD QUALITY SOFTWARE}

In software development, getting sufficient and correct requirements from the users is most important, because these requirements will determine the functionality of the system (Robertson \& Robertson, 1999). There are many methodologies are widely being used for software development process however those are almost invariantly tailored for urban users and their urban settings (Yeo et al., 2010) as the urban context and cultural elements of urban developers and users would have been "incorporated" in the design. It is argued that urban users, target audience of the software, would have a better education, and higher literacy than their rural counterparts. Also, work processes in existing organisations are likely to exist; software would need to be started from scratch with rural communities, as there may be little work done in that area. The challenge of building relevant software for rural communities exists within the 
complex web of their needs to be captured, needs that could not be fulfilled by merely providing technological tools. Moreover the rural community generally possess low education level and computer literacy thus this could hinder software acceptance from them if right approaches are not employed. As such, these implications suggest localising a software development methodology in building appropriate software product within the rural community. An appropriate software refers that it should be built in the way that to support and improve livelihood of the rural communities.

Good quality software exists when it fits the sociotechnological environment if it is to work in practice. From experience of successful telecentres, community participation is the key. We believe that to obtain good requirements based on the rural community needs would require their active participation in the process. Building software for rural communities should also incorporate the following:

- Community helps define the aims. The community is used to having their input into project objectives which address needs that they identify themselves.

- Community as the participants. It is important to having input from the community into every phase in project development. The project outcome has to be community assets hence empowering their participation is to promote a sense of belonging.

- Community describes the process. The community should have real influence on project direction in order to ensure that the outcome is relevant and benefit to the community (Moseley, 2003).

In addition, Scott, Denman, \& Lane (1989) describes community-based development project is action-oriented and requires community focus as the communities are often unfamiliar to carry out the initiatives. One approach that has been seen to be successful in engaging communities is the use of the participatory action research (PAR) approach. PAR is deemed an appropriate approach in the development of the software, where there exists a situation of openness and cooperation, social interactions, the need for change, being able to observe the effects that the changes brought about and also of the learning and understanding of what community was believed necessary.

\section{IMPORTANCE OF PARTICIPATION}

With the refocusing of development strategies in the mid 1970s, growing research efforts have been devoted to using alternative approaches to understand the organisation, behavioural and social consequences of development. Oakley (1995), a development scholar, reflected that this shift of focus has manifested by valuable lessons learnt about people's participation as a focus in development processes. He emphasised that the need for development strategies is to attempt to involve people more directly in the processes. This trend has continued and has led to the notion of participatory development in many fields, and applied in both rural and urban development.

Community participatory approach is believed to provide the opportunity for community to develop different assessment strategies tailored in response to the needs of their contexts (Harvey, 2008) that motivates them to take action to bring about changes in their social lives. They identify and explain their priorities and problems based on indigenous wisdom and view through joint planning and self-analysis. Moreover, community involvement conveys a sense of ownership so that they have commitment to the change process. Software development for rural communities should be stared from the premise that research are owned and controlled by the communities themselves, and hence it is an assurance to handover rural project sustainability to the local themselves.

\subsection{Participatory: Social development success in development projects}

Participatory research and development, a major paradigm shift, nowadays strongly guides the people-oriented concept of International Development and Research Centre (IDRC), an important international donor, in sustainable agricultural, natural resource management and rural livelihoods sectors. Research and development is now no longer the exclusive domain of scientists, but rather a joint process of learning investigating and seeking improvements in local situations, needs and opportunities involving the wider and meaningful participation of user groups (Gonsalves et al., 2005).

The growing interest in the use of participatory approaches in rural sectors has introduced several new fields which users are the experts - such as participatory rural appraisal, farmer participatory research, participatory technology development, participatory action research, participatory learning and action.

\subsection{Participatory - Success in $\mathrm{HCl}$ e.g. using participatory design approaches}

At present, most software development methodologies only call for user involvement during the early stage of process and thereafter little 
involvement before product delivery. Instead developers are the ones who decide how the software system should be built. There is a very significant empathic differentiation. With respect to user-centred design (UCD) philosophy and process, the needs of end users of a product, in particular their tasks and goals, should be given extensive attention and understanding. Given the problems to be resolved are derived from the users, potentially, they should participate during the problem exploration and definition, and focus ideas for solution within and with their context.

Participatory design (PD) is a pool of theories, practices, and studies that enable full participation of the end-users in leading the user-centred software and hardware development and computer-based activities (Muller, 2003). This diversity brought the researchers and practitioners together into uniting the design process to help ensure that the product is designed to meet the real needs and is usable. PD is an acknowledged UCD approach that follows the ISO-13407 humancentred design for interactive systems.

\section{ACTION RESEARCH}

The origins of action research (AR) are unclear within the literature, generally many authors (e.g. Kemmis \& McTaggert, 1988; Zuber-Skerritt, 1993) accredited Kurt Lewin, a social psychologist, as the person who first coined the term "action research" to study social psychology. Lewin (1946) described $\mathrm{AR}$ as a "comparative research on the conditions and effects of various forms of social action, and research leading to social change" that uses "a spiral of steps" where each is a cycle process of "planning, action, and fact-finding about the result of the action". During the post-war era, the Tavistock Institute of Human Relations in London developed a socio-technical approach, an extended work and theories of Lewin towards operational perspective, (Trist, 1976) to deal with psychological and sociological disorders among veteran of battlefields and prisoner-of-war camps.

Looking across the early development of $A R$, it inspired the desire of researchers to deal with important social problems (Kock, McQueen, \& Scott, 1995) in and between organisations. Over the past five decades, AR has continued and been employed in larger scale of social system. AR is typically understood as a cyclical and long learning process integrating theory and practice through change and reflection (Rapoport, 1970) by working with people rather than for people. Each cycle utilises a systematic methods of (a) planning action, (b) taking action, (c) observing the action taken and (d) evaluating and reflecting in prior planning the next cycle. The definition of $A R$ becomes confusing in a variety of literature, but there is a general agreement that AR is a pragmatic intervention applied by the researcher in real-life contexts of environment being researched. The technique is characterised as a moment-tomoment inquiry process of collaborative analysis and research to understand the underlying causes and envision social changes in the future (Reason \& Bradbury, 2004). Social problems are complex and many-sided, but the trouble may be traced from the "inside". For example in a rural area context, the rural communities and designers work together to identify and propose new courses of action that help them to improve their social practices. The action researchers coach the community by seeking multiple evidences to analyse and research the consequence to the action taken, in the light to fulfilling their responsibility in research tasks. By doing so the researcher is able to assure a commitment from the community of the system being studied (practitioners) by exerting positive intervention on the system and achieving both researcher and practical objectives.

\section{AR IN IS/IS DEVELOPMENT}

Action research is like a discovery phase of software development. Research is initiated by all collaborators coming together to address issues or problems in the targeted communities' lives and experiences - people learn best, and more willingly apply what they have learned, when they do it themselves (O'Brien, 2001). The process of discovering involves utilising a systematical cyclical method of planning, taking action, observing, evaluating and critical reflecting prior to planning the next cycle. We also agreed that action research is an approach of "learning by doing". Each process studies the real problems systematically and ensures the intervention is informed by theoretical considerations at the realworld situations.

\section{CASE FOR PARTICIPATORY ACTION RESEARCH}

As described above the usefulness of $A R$, the Participatory component is crucial, given the importance of active involvement of the communities. We also strongly believe that PAR is the right direction to go, it has been successfully used to build a telecentre, which is now being run and used by the community (removed for anonymity). Thus, we propose PRISMA (Participatory Action Research in Software Development Methodology Augmentation), a composition of "participation" and "action research" in software engineering. 


\subsection{PRISMA: PAR in Software Development methodology}

Conventional software development approaches emphasise the "hard" aspects of problem domain, which typically deal with the technological terms of hardware and software systems, nevertheless the role of the opposite aspect has received comparatively less attention. A "hard" approach is prescriptive and might be applied fairly consistently between organisations and within organisations (Avison et al., 1999), we believe there is a pragmatic value for emphasising the "soft" aspects to obtain good requirements. These "soft" side in software development concerns on the role for humanistic inside the fuzzy world of multidisciplinary organisational, political and social systems. These people work in varying environment, possess different backgrounds, attitudes and expectations, and perceive conflicting views from one another. And sometimes people change over time during development. Failure to consider these non-technical factors in software design and development may affect user requirements and expectations, poor system design, inefficient and ineffective user interface, overdue, over budget, and the rickety list goes on.

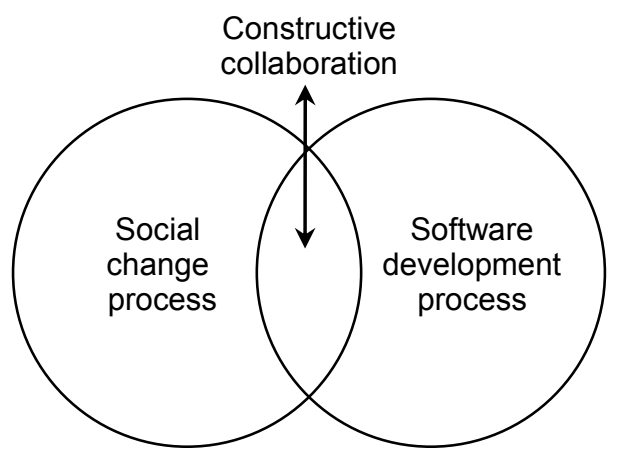

Figure 2: PRISMA framework

In this paper, we argue that rural development is community-oriented, and hence software development for rural communities has to be participatory to community-driven approach analysis, planning, monitoring and evaluation. PRISMA is a community-based software engineering for rural communities approach that combines software development method and facilitates social change process with community participation strategies to bridge the gap between knowledge produced through research and translation of this research into software intervention for rural areas (see Figure 2). We believe societal challenge in rural communities can be addressed, at least in part by collaborative work that lies at the intersection of researching social change and developing software production for rural communities. The whole PRISMA cycle is illustrated in Figure 3, undertaken and combined the processes in learning cycle of action research (adapted from Avison and Wood-Harper, 1991) and the conventional processes in software development life cycle.

(1)

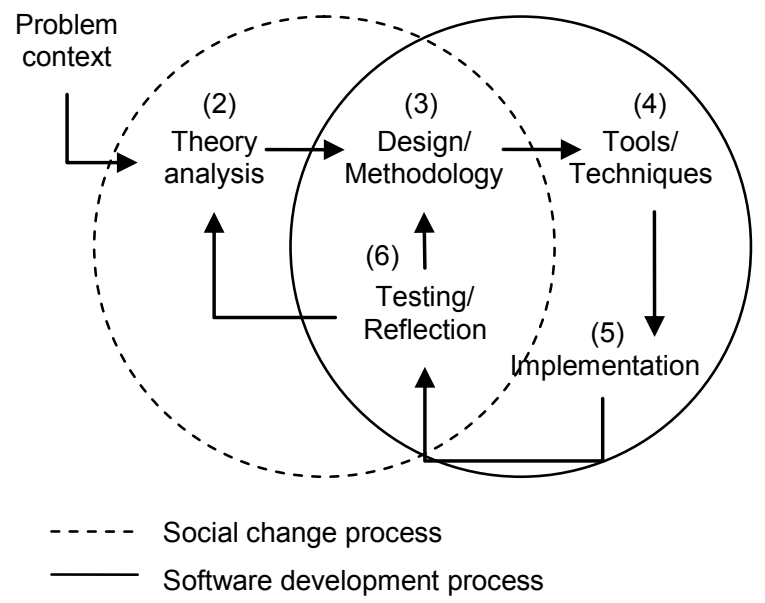

Figure 3: In depth of PRISMA

When developing software in rural communities, the domain of studying software design is clearest where the human organisation interacts with software system that will help them empower their daily activities. From a rural social-organisational viewpoint, when new software system is introduced, it has to intervene in the form of a positive change process in their practices to achieve work effectiveness. Hence, we set action research (of participatory action research) at the beginning of PRISMA approach, to (1) identify the real life problem that are the underlying causes of the rural communities' desire for change, and consider if the problem being researched will make a difference for them. This identification will be served to (2) clarify the area of focus and develop a few theoretical assumptions about the problem situation. At this point, we emphasise the importance of active community participation. The rural community should participate in joint theory analysis with researchers, given equitable power over defining research aims and direction, making smart local decisions, and drawing local conclusion from it. Thus, AR provides a podium for developing valid knowledge that connects the local knowledge of the stakeholders and society's needs. As a result of this "building theory" research, the design and methodology framework (3) will be discovered and defined within the collaboration from the researchers, rural communities and software developers. This step acts like action planning phase in AR to establish the target for change, and design phase in software development process to establish the approach to change, and includes techniques and tools to be used (4). After system features and operations are described in the planned action, it is then ready to "converted" into a software system in programming codes (5). This step is seen as an action-taking phase that 
implements the planned action. After the actions, the software system, are completed, there is a need of collaborative of all stakeholders undertake the system testing and reflection of the outcomes (6). This evaluation stage will reveal whether the theoretical effects of the action have been realised, and whether these effects relieved the problems. If the action taken brings successful change, the evaluation must critically question whether the undertaken action, among the myriad routine and non-routine organisational actions, was the sole cause of success. If the change is unsuccessful, some feedbacks to step 2 (theories adjustments) and 3 (refine new approaches) for the next iteration should be established.

\section{USE OF LAU'S AR FRAMEWORK TO SHOW PRISMA IS AR}

This method provides a model for making sure the community drives the technology (i.e. the locally relevant software to the particular rural area), but not the other way around. By adapting IS-AR research framework modelled by Lau (1999), we define criteria of PRISMA by which software engineering research studies should be conducted and assessed in the following four dimensions:

- Conceptual foundation as its underpinnings;
- Study design to describe the methodological details;

- Research process of diagnosis, actions, reflection and general lessons; and

- Respective role of the researcher and participants.

PRISMA uses these dimensions to deploy a software development criterion that is capable in supporting cooperative and social aspects of software engineering (see Table 1).

From the assessment, PRISMA is considered AR given that the classification of $A R$ is well covered by PRISMA's characteristics.

\section{CONCLUSION AND FURTHER WORKS}

Through case studies of PRISMA's use, we believe it will not only build software appropriate for the rural communities, but also, provide further details to improve software development methodologies.

From the table and the discussion above, we believe PRISMA is appropriate for the development of software for rural communities. To determine its efficacy, PRISMA is currently being employed to develop software for rural communities in domains of health, education and business (tourism).

Table 1: Assessment PRISMA using Lau's IS action research framework

\begin{tabular}{|c|c|c|}
\hline \multicolumn{2}{|c|}{ Dimension and criteria } & Classification in PRISMA \\
\hline \multirow{3}{*}{$\begin{array}{l}\text { Conceptual } \\
\text { foundation }\end{array}$} & Aim/Question & $\begin{array}{l}\text { The rural communities' perceptions of their practices are embedded in their } \\
\text { normal patterns of action, which need to be understood in order to design, } \\
\text { implement, and evaluation the projects. }\end{array}$ \\
\hline & $\begin{array}{l}\text { Assumptions } \\
\text { Perspective/tradition }\end{array}$ & Define the assumptions that exists \\
\hline & Stream & $\begin{array}{l}\text { Participatory Action Research - Community participation in software } \\
\text { development on their own behalf }\end{array}$ \\
\hline \multirow{9}{*}{$\begin{array}{l}\text { Study } \\
\text { Design }\end{array}$} & Background & The challenges in technology acceptance and adoption \\
\hline & Intended change & $\begin{array}{l}\text { Software development for rural communities is definitely bringing deep and } \\
\text { significant social change to them. }\end{array}$ \\
\hline & Site & Rural areas \\
\hline & Participants & $\begin{array}{l}\text { Villagers are the target audience; } \\
\text { Background identified (poor, some illiterate) health problems identified }\end{array}$ \\
\hline & Data sources & Participant's view and observation, interviews, focus group \\
\hline & Duration & Depends on the project \\
\hline & Degree of openness & All processes are transparent to both researchers and community \\
\hline & Access/exit & Appropriate access through the formal protocol; Exit when community is aware \\
\hline & Presentation & Can use interviews with emphasis of the results, as well as lessons learnt. \\
\hline \multirow{5}{*}{$\begin{array}{l}\text { Research } \\
\text { Process }\end{array}$} & Problem Diagnosis & Research problem identified (all in tandem with the social change) \\
\hline & Action interventions & Interventions/engagement with community to build software (e.g. design) \\
\hline & Reflective learning & Reflect whether the goals achieved \\
\hline & Iteration & Iterative improvement by reflection is conducted \\
\hline & General Lessons & On reflection of the project, lessons learnt can be drawn \\
\hline \multirow{4}{*}{$\begin{array}{l}\text { Role } \\
\text { expectations }\end{array}$} & Researcher & Researcher knows how to deal and facilitate the community \\
\hline & Participants & $\begin{array}{l}\text { Participants are actively involved throughout the process } \\
\text { Involved in data collection, design, and also dissemination. }\end{array}$ \\
\hline & Competency & $\begin{array}{l}\text { Community should be competent, effective in completing the roles in software } \\
\text { development and research. They will eventually gain competency on the } \\
\text { sustainability. }\end{array}$ \\
\hline & Ethics & Ethical issues addressed: Community first, technology is secondary \\
\hline
\end{tabular}




\section{ACKNOWLEDGEMENTS}

The authors acknowledges resaerch funding received from at Universiti Malaysia Sarawak, the Malaysian Ministry of Science Technology and Innovation, and Official Development Assistance (Japan).

\section{REFERENCES}

Avison, D., \& Wood-Harper, A. (1991). Information System Development Research: An Exploration of Ideas in Practice. Computer Journal , 34 (2).

Avison, D., Lau, F., Myers, M., \& Nielsen, P. (1999). Action Research. Communication of the ACM , 42 (No. 1).

Gonsalves, J., Becker, T., Braun, A., Campilan, D., De Chavez, H., Fajber, E., et al. (Eds.). (2005). Participatory Research and Development for Sustainable Agriculture and Natural Resource Management: A Sourcebook. International Potato Center-Users' Perspectives With Agricultural Research and Development, Laguna, Philippines and International Development Research Centre, Ottawa, Canada.

Harvey, M. (2008). The role of participatory action research in leading the development of engaging assessment. Macquarie University, Learning and Teaching Centre.

Kemmis, S., \& McTaggert, R. (1988). The Action Research Planner. Victoria: Deakin University Press.

Kock, N., McQueen, R., \& Scott, J. (1995). A Methodology to IS Study in Organisations through Multiple Action Research Cycles. Research Report, University of Waikato, Department of Management Systems, New Zealand.

Lau, F. (1999). Toward a framework for action research in information systems studies. Information Technology \& People , 12 (2), 148-176.

Lewin, K. (1946). Action Research and Minority Problems. Journal of Social Issues , 2 (4), 34-46.

Mayanja, M., Acevedo, M., Caicedo, S., \& Buré, C. (2010). Guidebook for managing telecentre networks : Engineering a new phase of the telecentre movement. http://idlbnc.idrc.ca/dspace/bitstream/10625/41215/1/12911 8.pdf (January 31, 2011)
Moseley, M. (2003). Rural developent: principle and practice. London: SAGE Publications Ltd.

Muller, M. (2003). Participatory design: the third space in HCl. In J. Jacko, \& A. Sears, The humancomputer interaction handbook (pp. 1051--1068). New Jersey, USA: L. Erlbaum Associates Inc.

Oakley, P. (1995). People's Participation in Development Projects. Occasional Paper Series, No. 7. Oxford.

O'Brien. (2001). $n$ Overview of the Methodological Approach of Action Research. In R. Richardson, Theory and Practice of Action Research. João Pessoa, Brazil: Universidade Federal da Paraíba.

Rapoport, R. (1970). Three Dilemmas in Action Research. Human Relations , 23 (6), 499-513.

Reason, P., \& Bradbury, H. (2001). Handbook of Action Research: Participative Inquiry and Practice. London: SAGE Publications, Inc.

Robertson, S., \& Robertson, J. (1999). Mastering the Requirements Process (2nd Edition ed.). Addision-Wesley Professional.

Roman, R. a. (2002, January). Themes and Issues in Telecentre Sustainability. Development Informatics Working Paper No. 10.

Scott, I., Denman, J., \& Lane, B. (1989). Doing by learning: $A$ handbook for organisers and tutors of village-based community development courses. Cirencester, UK: Association of Rural Community Councils.

Trist, E. (1976). Engaging with Large-scale Systems. In A. Clark, Experimenting with Organizational Life: The Action Research Approach (pp. 43-75). New York: Plenum.

UNESCAP. (2008, April). Overview of telecentre development in the Asia and Pacific Region. http://www.unescap.org/idd/events/ADB-CeC-

Subreg-

2008/pdf/Agenda\%20ltem3/ESCAP_regional\%20o verview_rev4.pdf (February 8, 2011)

Yeo, A., Ng, E., Flora, S., \& Nurul, Z. (2010). Community-Centered Software Development Methodology: Developing Usable Software for Remote Communities. International Workshop on Internationalisation of Products and Systems .

Zuber-Skerritt, O. (1993). Improving Learning and Teaching Through Action Learning and Action Research. Higher Education Research and Development , 12, 45-58. 